\title{
Advanced acoustic emission analysis of brittle and porous rock fracturing
}

\author{
S. Stanchits ${ }^{1, \mathrm{a}}$, and G. Dresen ${ }^{1}$
}

${ }^{1}$ GFZ German Research Centre for Geosciences, Telegrafenberg D423, 14473 Potsdam, Germany

\begin{abstract}
Analysis of Acoustic Emission (AE) induced during brittle and porous rock fracturing at variety of loading conditions has been performed. On the base of advanced analysis of $\mathrm{AE}$ parameters, ultrasonic velocities and mechanical data we found that regardless of applied loading conditions the process of rock fracture can be separated into two main stages: (A) accumulation of non-correlated cracks localized almost randomly in the whole volume of uniformly stressed rock. (B) Final stage of sample fracturing could be characterized by appearance of $\mathrm{AE}$ nucleation site followed by initiation and propagation of the macroscopic fault. Contribution of tensile sources is reduced significantly, shear type and pore collapse type events dominate during propagation of a fracture process zone through the sample regardless of applied loading conditions. In the case of porous rock, nucleation of compaction bands could be clearly identified by the appearance of AE clusters inside the samples. Microstructural analysis of fractured samples shows excellent agreement between location of AE hypocenters and faults or the positions of compaction bands, confirming that advanced $\mathrm{AE}$ analysis is a powerful tool for the process of rock fracture investigation.
\end{abstract}

\section{Introduction}

There are three basic crack modes identified: Mode I (extension, opening), Mode II (in-plane shear) and Mode III (out of plane shear). For most brittle materials tensile failure (Mode I) is predominant at low confining pressures, but with increasing confining pressures shear cracks and mixed mode cracking become more significant [1]. As tensile fracturing is frequently observed in nature, it has been studied intensely, not only in terms of fracture mechanics, but also using acoustic emission technique [2-3]. On the contrary, shear fracturing has been less studied in the past, mainly due to a lack of reliable techniques to separate tensile and shear cracks. Recently, a new method has been proposed, based on the polarity analysis of AE first motions [4-5]. It has been shown that even for Mode II or pure shear loading, a high percentage of tensile cracks has been registered [6].

Three different deformation modes can be observed in porous sandstone [7-9]: when subjected to an overall compressive loading, a rock can fail by shear localisation, compaction localisation or cataclastic flow. Although dilatancy is generally observed as a precursor to brittle faulting and to the development of shear localisation, recent field [10] and laboratory [8-9, 11-13] observations have also focused attention on the formation of localised compaction bands in porous sandstones.

\footnotetext{
a e-mail : stanch@gfz-potsdam.de
} 
Compaction bands are narrow planar zones of material that form with or without apparent shear. They extend in planes perpendicular to the main compressive stress. Laboratory experiments have shown that compaction bands occur in dry and saturated sandstones with porosities ranging from 20 $28 \%$, deformed at room temperature. Compaction bands display significantly reduced porosity and act as barriers for fluid flow [14-15]. This suggests that the presence of compaction bands may affect fluid circulation in the crust, extraction of oil and gas from reservoir rocks, groundwater circulation in aquifers, as well as the sequestration of carbon dioxide.

\section{Experimental techniques}

\subsection{Sample materials}

Investigations of brittle fracture were performed on granite samples from Aue, Germany having an initial density of $2.62 \mathrm{~g} / \mathrm{cm}^{3}$ and an initial porosity of $1.3 \%$. Mineral composition of granite contains $30 \%$ quartz, $40 \%$ plagioclase, $20 \%$ potassium feldspar and $10 \%$ mica [16]. Grain sizes ranges from $0.9-1.8 \mathrm{~mm}$ with an average value of $1.3 \mathrm{~mm}$. Microstructure analysis of undeformed Aue granite yielded crack densities in the range of $0.3-0.6 \mathrm{~mm}^{-1}$ [17]. Investigations of compaction bands were performed on specimens prepared from Bleurswiller sandstone exposed in the Vosges mountains in eastern France (Frain Quarry). Bleurswiller is gray sandstone containing 50\% quartz, 30\% feldspars, and $20 \%$ oxide micas. Porosity is about $25 \%$, grain sizes range from $0.08-0.15 \mathrm{~mm}$ with a mean value of approximately $0.11 \mathrm{~mm}[12]$.

\subsection{Testing procedure}

Cylindrical samples of brittle and porous rock of $50 \mathrm{~mm}$ diameter and 100-125 mm length were fractured using a servo-controlled 4.6 MN loading frame from Material Test Systems (MTS) with a stiffness in compression of $11 \times 109 \mathrm{~N} \mathrm{~m}^{-1}$ equipped with a confining pressure vessel (Figure 1a). Formation of compaction bands was investigated in wet sandstone; the samples were saturated with distilled water and deformed under drained conditions at constant pore pressure of $10 \mathrm{MPa}$. Variation of pore volume throughout a test was determined using a volumometer, allowing the evolution of connected sample porosity to be monitored. Local strains were measured by two pairs of strain gauges glued directly onto the sample surface.
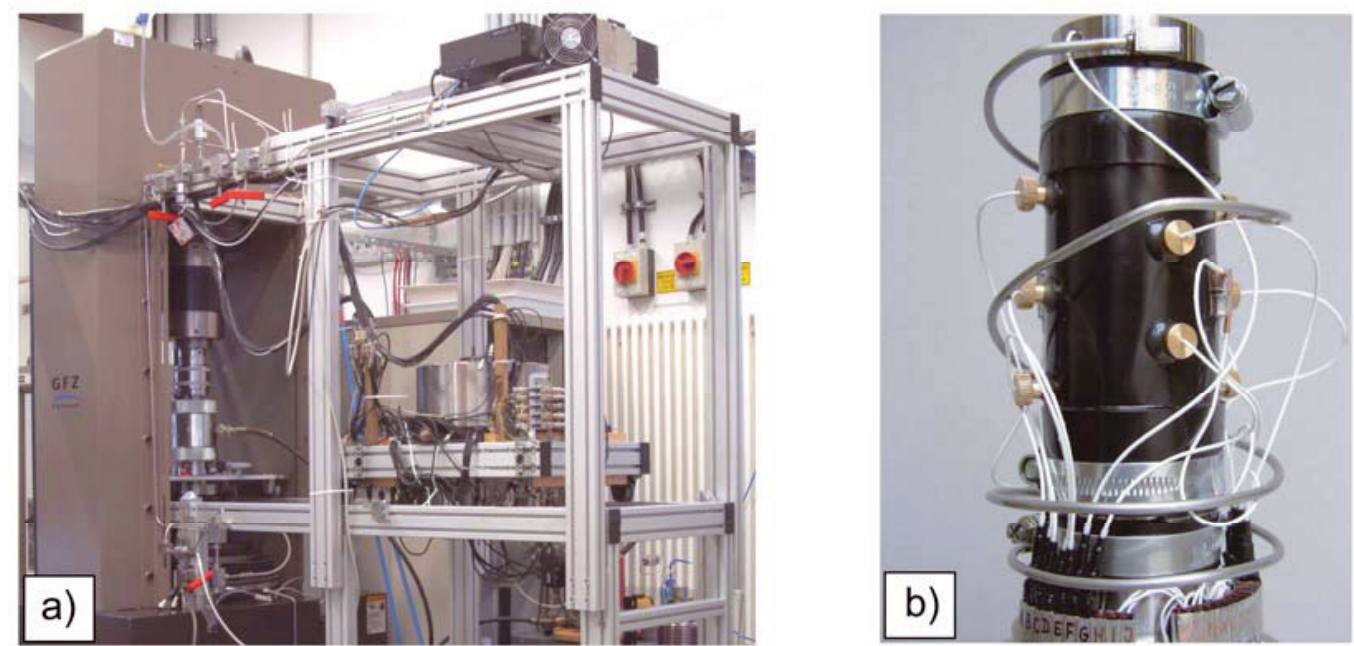

Figure 1 MTS loading frame (a) and sample in rubber jacket with installed P- and S- piezoelectric sensors (b) 
Brittle and porous rock samples were subjected to two types of loading: All samples were first subjected to hydrostatic pressure $\left(\sigma_{1}=\sigma_{2}=\sigma_{3}\right)$ increasing up to a fixed pressure level at a rate of $1-1.5$ $\mathrm{MPa}$ per minute, then an axial stress was applied to the specimens. Axial loading rate was servocontrolled using the AE rate recorded by a piezoceramic sensor attached to the sample. For porous rock, the confining pressure was at first increased to $5 \mathrm{MPa}$ and samples were saturated with distilled water. Three triaxial experiments were conducted with porous rock at confining pressures of 60,80 , and $100 \mathrm{MPa}$ at a constant axial strain rate of $10^{-5} \mathrm{~s}^{-1}$. At the end of each experiment, the samples were unloaded, impregnated with blue epoxy, and thin sections were prepared for microstructural analysis.

\subsection{Acoustic emission and ultrasonic velocities monitoring}

AE activity and velocity changes were monitored by twelve P-wave and eight S-wave piezoelectric sensors either embedded in the pistons or glued to the sample surface and sealed in a Neoprene jacket with two-component epoxy (Figure 1b). To analyse stress-induced shear wave splitting, we installed four S-wave piezoelectric sensors polarised in the vertical and horizontal directions. P- and $\mathrm{S}$-wave sensors were produced from PZT piezoceramic discs with $5 \mathrm{~mm}$ diameter and $1 \mathrm{~mm}$ thickness and square shape piezoceramic plates $5 \times 5 \times 1 \mathrm{~mm}$, respectively. The thickness and diameter-related resonant frequencies of the P-wave sensors were about $2 \mathrm{MHz}$ and $500 \mathrm{KHz}$, respectively. In case of porous rock, P-wave sensors were produced from PZT piezoceramic discs with $5 \mathrm{~mm}$ diameter and $2 \mathrm{~mm}$ thickness, and the thickness-related resonant frequency of the P-wave sensors was about $1 \mathrm{MHz}$.

Transducer signals were amplified by $40 \mathrm{~dB}$ using Physical Acoustic Corporation (PAC) preamplifiers equipped with $100 \mathrm{kHz}$ high-pass filters. Full-waveform AE data and the ultrasonic signals for $\mathrm{P}$-wave and $\mathrm{S}$-wave velocity measurements were stored in a 16 channel transient recording system (DAXBox, PRÖKEL, Germany) with an amplitude resolution of 16 bit at $10 \mathrm{MHz}$ sampling rate. For periodic elastic wave speed measurements we used six P-sensors and four Ssensors as senders applying $100 \mathrm{~V}$ pulses every 30-40 seconds during the loading. Ultrasonic transmissions and $\mathrm{AE}$ waveforms were discriminated automatically after the experiments.

All waveforms were recorded without any dead time between consecutive signals and, during periods of high AE activity, signals were recorded continuously. To locate AE hypocenters, P-wave onset time was picked automatically using different criteria including Akaike's information criterion [18]. Hypocentre locations were estimated considering time-dependent changes of the anisotropic velocity field. We estimate the AE location accuracy to be about $2 \mathrm{~mm}$. First motion amplitudes were picked automatically and first motion polarities were used to discriminate AE source types in tensile, shear and collapse events [4].

\section{Experimental results}

\subsection{Deformation of brittle rock}

Figure 2 shows time history of mechanical data, ultrasonic velocity and variation of AE parameters registered during fracturing of intact granite sample under $10 \mathrm{MPa}$ confining pressure. At the beginning of loading about $80 \%$ of AEs were identified as tensile type (Figure 2e) indicating appearance of dilatational cracking localized almost randomly in the whole sample (Figure 2a). During the nucleation stage of fracturing (Figure $2 \mathrm{~g}$ ) the relative proportion of tensile cracks decreased significantly, and proportion of shear cracks increased (Figure 2e). Decrease of horizontal velocity components (Figure 2c) closely correlates with onset of significant acoustic emission activity (Figure 2b) and with the maximum of volumetric strain (Figure 2f). Therefore acoustic emission, ultrasonic velocities and strain characteristics allow reliable separation of the initial and the nucleation stages of the sample fracturing. 


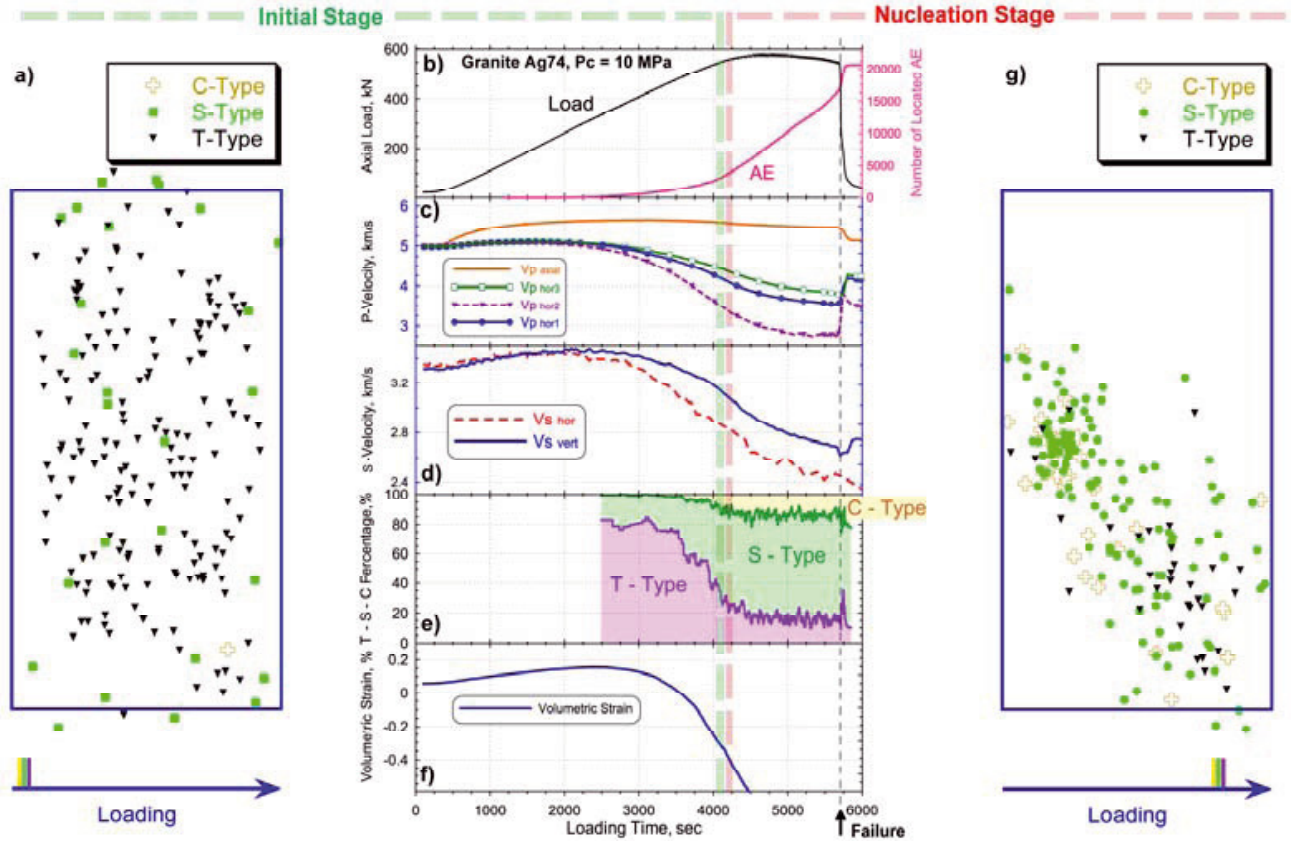

Figure 2. Location of AE hypocenters during initial stage of granite fracturing under $10 \mathrm{MPa}$ confining pressure (a); loading history (b); P- and S- ultrasonic velocities (c,d); separation of Tensile-Shear-Collapse types of AE events (e); variation of volumetric strain (f), and AE location during final stage of fracturing (g).
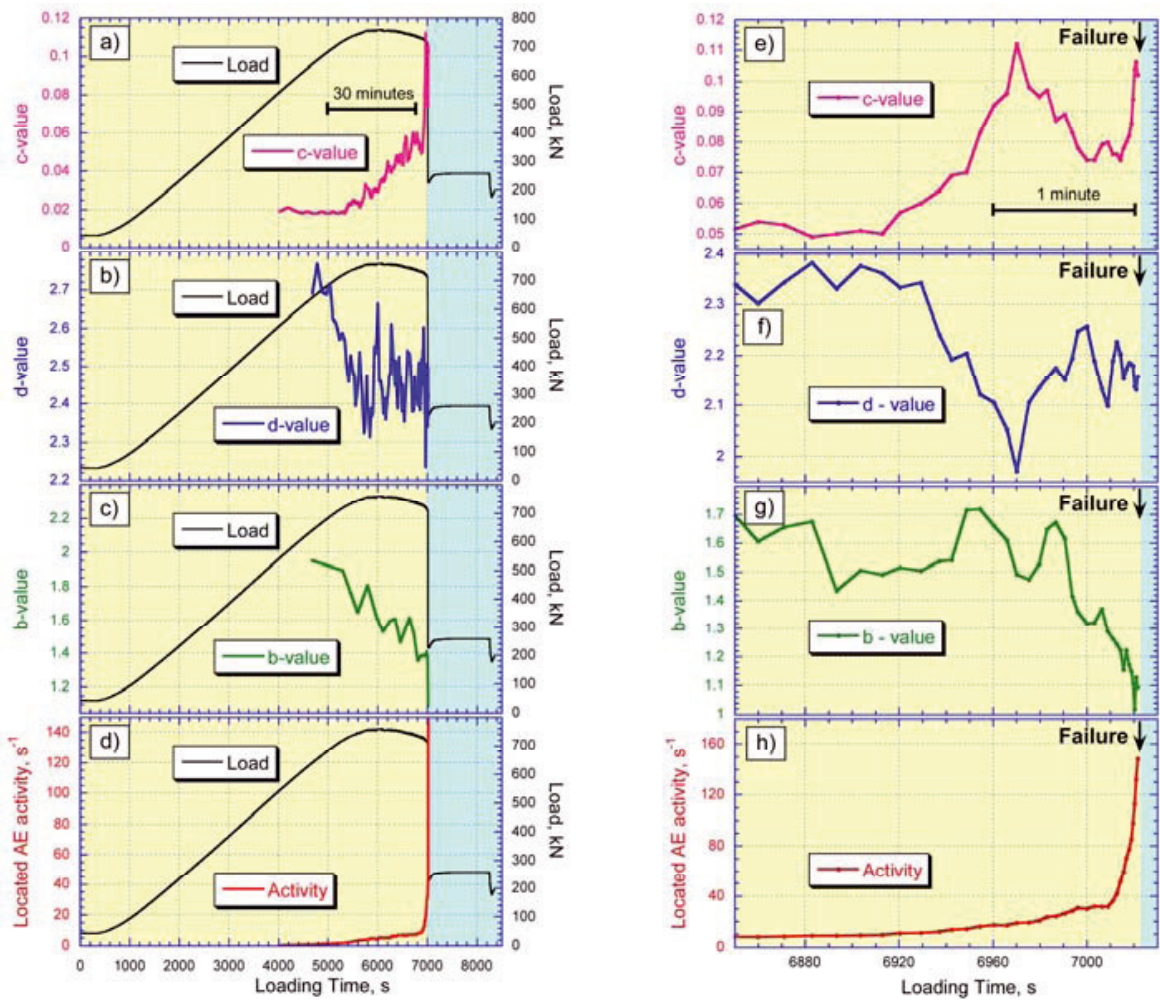

Figure 3. Loading curve and correlation coefficient c-value (a,e); fractal dimension coefficient d-value (b,f); slope of frequency-amplitude distribution b-value $(\mathrm{c}, \mathrm{g})$ and $\mathrm{AE}$ activity $(\mathrm{d}, \mathrm{h})$ versus time of granite sample loading, fractured at $20 \mathrm{MPa}$ confining pressure. 
The results of statistical analysis of AE registered during granite sample fracturing at $20 \mathrm{MPa}$ confining pressure are presented in Figure 3. Fractal dimension coefficient (d-value) was calculated as a slope of the correlation integral C(r), according to [19]. Correlation coefficient (Figure 3a,e) was calculated according to [4] as the value of correlation integral $\mathrm{C}(\mathrm{r})$ at the distance $1 \mathrm{~cm}$. At the beginning of loading, d-value is close to 2.8 (Figure $3 \mathrm{~b}$ ), which is interpreted as accumulation of almost randomly distributed cracks. Later decrease of d-value was accompanied by an increasing correlation coefficient (Figure 3a). This may be interpreted as localization of cracking in the fracture process zone before final failure of the sample. Similar behaviour of the d-value was observed earlier in [20]. Negative slope of cumulative frequency-amplitude distributions (b-value) was calculated according to [21]. Decrease of b-value (Figure 3c) could be interpreted as enlargement of cracks, following by an avalanche-type increase of acoustic emission activity (Figure 3d). Detailed analysis of statistical parameters preceding failure of the sample shows that shortly before failure correlation coefficient increased (Figure 3e) and d-value decreased (Figure 3f), indicating localization of failure. Subsequently drop of b-value indicates enlargement of cracks (Figure $3 \mathrm{~g}$ ) and fracture propagation accelerated (Figure $3 \mathrm{~h}$ ). Therefore, first we observed localization of fracture, then enlargement of fractures, following by acceleration of fracture process, preceding the final failure (Figure 3 ).

\subsection{Deformation of porous rock}

The results obtained during deformation of three Bleurswiller sandstone samples conducted at confining pressures of 60,80 , and $100 \mathrm{MPa}$ show that as long as a hydrostatic pressure was applied, sample compaction remained purely elastic, but with increasing differential stress, however, inelastic compaction started at a certain critical stress state $\mathrm{C}^{*}$. During hydrostatic loading, $\mathrm{P}$ and $\mathrm{S}$ wave velocities first increase, however, after onset of inelastic compaction at $C^{*}$, elastic wave velocities start to decrease, accompanied with slight increase of P-wave anisotropy $\left(\mathrm{A}_{\mathrm{P}}\right)$. Comparison of stressinduced anisotropy in porous $\left(A_{P}<4 \%\right)$ and brittle rock $\left(A_{P} \approx 35-40 \%\right)$ indicates that the formation of compaction bands does not produce strong elastic anisotropy. After the tests, the samples were unloaded, impregnated with blue epoxy and cut into halves parallel to the long sample axis and the maximum compressive stress direction. In Figure $3 \mathrm{AE}$ hypocenters and the photo of sandstone sample deformed at $60 \mathrm{MPa}$ confining pressure are shown.
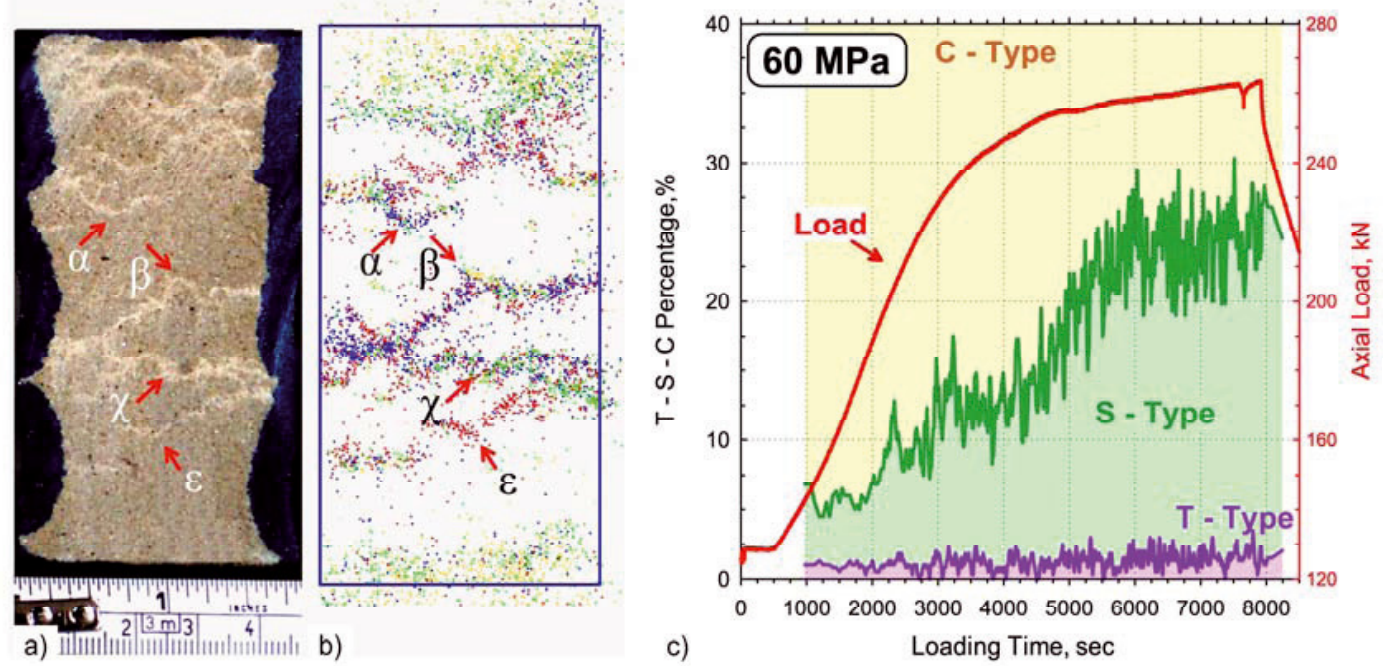

Figure 3 Photo of sandstone sample after deformation at $60 \mathrm{MPa}$ confining pressure (a); AE hypocenters recorded during deformation (b); modes of crack propagation during the formation of compaction bands and axial load versus time (c)

Light areas in the photo (Figure 3a) correspond to highly damaged areas of sandstone, or compaction bands. The AE hypocenter distribution shows perfect agreement with the location of 
deformation bands (see $\alpha, \beta, \chi$ and $\varepsilon$ in Figures $3 \mathrm{a}$ and $3 \mathrm{~b}$ ). Close correspondence between Figure $3 \mathrm{a}$ and Figure $3 \mathrm{~b}$ show that AE hypocenters are an excellent proxy for studying the nucleation and propagation of compaction bands. Implosion-type events represent the dominant source type recorded before and during the formation of compaction bands (Figure 3c). We relate C-type events to pore collapse, S-type events to shear cracks and T-type to tensile cracks (Figure 3c).

\section{Discussion and Conclusions}

After deformation all fractured samples were impregnated with blue epoxy and optical thin sections were analysed. In case of deformed granite sample (Figure 4a) we observed existence of the dense system of almost parallel microcracks having sizes close to the grain size (an echelon cracks). These possibly result in stress induced anisotropy of elastic wave velocities (Figure 2c) and in existence of high percentage of tensile sources during initial stage of loading (Figure 2e). We suggest that during later stages of loading main macroscopic fault could crosscut the system of these echelon cracks, resulting in substantial increase of shear-type events, largely at the expense of tensile events (Figure 2e).
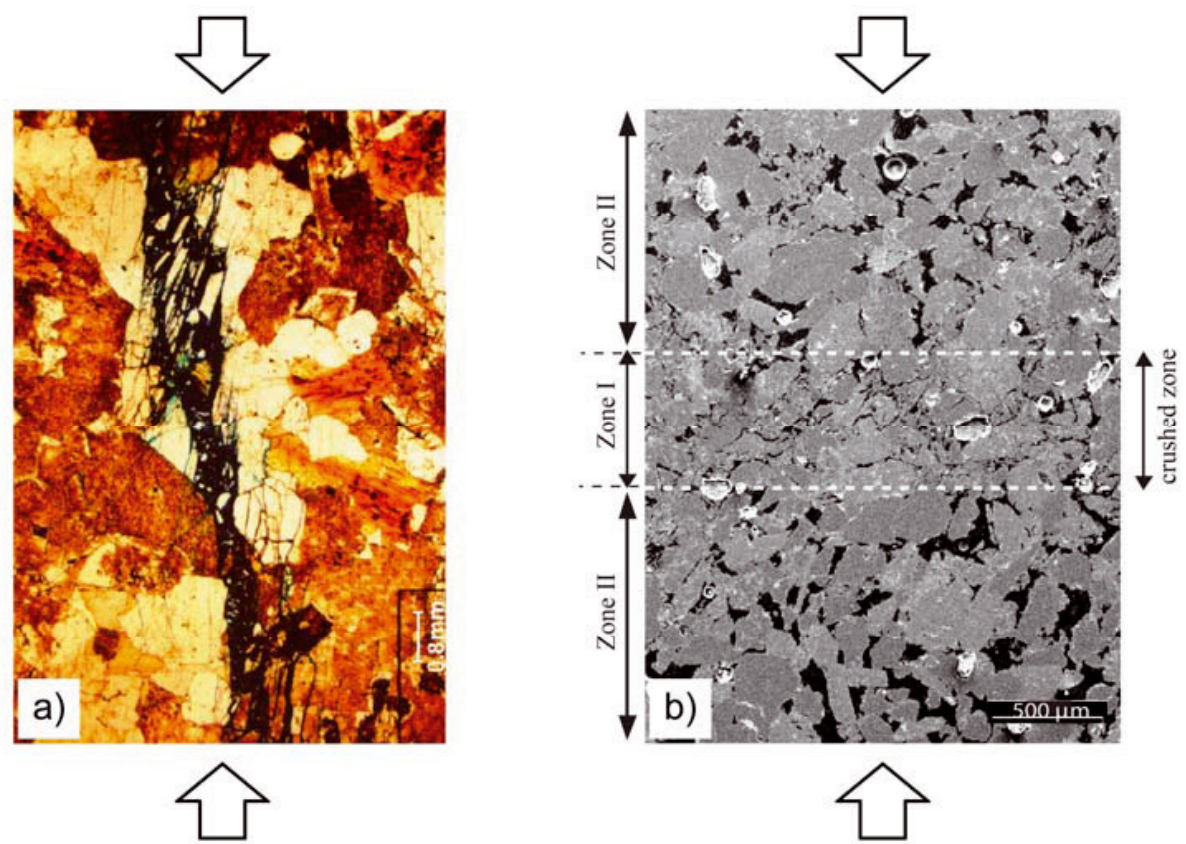

Figure 4 Microphoto of fractured granite thin section (a) and backscattered SEM micrographs revealing details of grain crushing inside the compaction band in sandstone (b)

The SEM micrograph (Figure 4b) of deformed sandstone sample demonstrates that the dominant micromechanism leading to the formation of compaction bands is grain crushing. This is in agreement with observations on Berea sandstone [22] and Castelgate sandstone [23], and also with observations of compaction bands in Bentheim sandstone [24]. Furthermore, our SEM micrograph also shows that within a compaction band, the orientations of cracks are highly variable (Figure $4 \mathrm{~b}$ ), which is in agreement with the fact that the elastic anisotropy remains small.

We found that implosion-type events represent the dominant source type recorded before and during the formation of compaction bands (Figure 3c), we relate these C-type AE events to pore collapse. During propagation of compaction bands S- and C-type events represent about $24 \%$ and $72 \%$ of the source mechanisms, respectively, and tensile cracks represent less than $4 \%$. The observations are in agreement with other studies [16, 25-26]. 
In our study we investigated the evolution of acoustic emissions activity, compression and shear wave velocities and volumetric strain in hydrostatic and triaxial compression tests of brittle rock (Aue granite) and of high porosity rock (Bleurswiller sandstone). In triaxial compression experiments, pronounced P-wave anisotropies and shear wave birefringence develop in loaded granite. With increasing differential stress $\mathrm{AE}$ activity in granite increased with a significant contribution of tensile events. Close to failure the relative contribution of tensile events and the speed of horizontally oriented elastic waves decreased. A concomitant increase of double-couple events suggests shear cracks connect previously formed tensile cracks. Advanced analysis of ultrasonic velocities, mechanical and AE parameters allow reliable separation of the initial and the nucleation stages of the sample fracturing (Figure 2) and analysis of AE statistical characteristics could be successfully applied to monitor the approaching final macroscopic failure (Figure 3).

In Bleurswiller sandstone, AE hypocenter distribution shows excellent agreement with the location of compaction bands. Nucleation and growth of compaction bands occurs as localised grain crushing and pore collapse. Initial loading and associated crack closure produced a transient velocity increase. However, with progressive loading and localised shear-enhanced compaction of the samples $\mathrm{P}$ and $\mathrm{S}$ wave velocities decreased drastically. The velocity decrease is assumed to reflect enhanced microcracking associated with grain crushing and pore collapse. We found that implosiontype of $\mathrm{AE}$ events, related to pore collapse represent the dominant source type recorded during porous rock fracturing and that contribution of shear type of $\mathrm{AE}$ events increased during the formation of compaction bands.

Therefore, detailed analysis of AE and ultrasonic velocities allows us recognition of the current stage of both brittle and porous rock fracture. Appearance of dilatancy in brittle rock and compaction bands in porous rock could be reliably identified and monitored by advanced AE and ultrasonic velocities analysis.

\section{Acknowledgements}

This work benefited from collaboration and productive discussions with many scientists. Among them, we would like to particularly thank Jerome Fortin and Yves Gueguen, Ecole Normale Superieure, Paris, France. Also we acknowledge Stefan Gehrmann for thin sections preparation.

\section{References}

1. S. Melin, Material Construction, 22, 23-27 (1989)

2. S.D. Glaser and P.P. Nelson, Int. J. Rock Mech. \& Min. Sci., 10, 53-67 (1992)

3. W.K. Zietow and J.F. Labuz, Int. J. Rock Mech. \& Min. Sci., 35, 291-299 (1998).

4. Zang, F.C. Wagner, S. Stanchits, G. Dresen, R. Andresen, and M.A. Haidekker, Geophys. J. Int., 135, 1113-1130 (1998)

5. S. Stanchits, S. Vinciguerra S. and G. Dresen, Pure appl. Geophys., 163, 974-993 (2006)

6. S. Stanchits and G. Dresen, G. Int. Symp. Non-Destructive Testing in Civil Engineering (NDTCE), Berlin, Germany, p. 107 (2003)

7. T.F. Wong, C. David, C. and W. Zhu, J. Geophys. Res., 102, 3009-3025 (1997)

8. E. Klein, P. Baud, P., T. Reuschle, and T-F. Wong, T-F. Phys. Chem. of the Earth, Part A, 26, 21-25 (2001)

9. J. Fortin, A. Schubnel, and Y. Gueguen, Int. J. Rock Mech. \& Min. Sci., 42, 873-889 (2005)

10. P.N. Mollema, and M.A. Antonellini, Tectonophysics, 267, 209-228 (1996)

11. B.C. Haimson, B.C. Phys. Chem. of the Earth, Part A, 26, pp. 15-20. (2001)

12. J. Fortin, S. Stanchits, G. Dresen, and Y. Gueguen, J. Geophys. Res., 111, B10203 (2006)

13. S. Stanchits, J. Fortin, Y. Gueguen and G. Dresen, Pure appl. Geophys., 166, 843-868 (2009)

14. D.J. Holcomb, and W.A. Olsson, J. Geophys. Res., 108, (B6), 2290, doi:10.1029/2001JB000813. (2003) 
15. V. Vajdova, P. Baud, and T-F. Wong, J. Geophys. Res., 109, B10406, doi:10.1029/2003JB002942. (2004)

16. A. Zang, F.C. Wagner, S. Stanchits, C. Janssen, and G. Dresen, J. Geophys. Res., 105, B10, 23,651-23,661 (2000)

17. C. Janssen, F.C. Wagner, A. Zang, and G. Dresen, Int. J. Earth Sci., 90, 1, 46-59. (2001)

18. M. Leonard, and B.L.N. Kennett, Phys. Earth and Plan. Inter., 113 (1-4), 247-263 (1999)

19. T. Hirata, T. Satoh, and K. Ito, Geophys. J. R. astr. Soc., 90, 369-374. (1987)

20. D. Lockner and J. Byerlee, In Proc. 5th Conf. on AE /Microseismic activity in Geologic Structures and Materials, 45-58, ed. Hardy, H.R., Trans-Tech, Clausthal-Zellerfeld, Germany. (1995)

21. B. Gutenberg and C.F. Richter, Seismicity of the Earth, Princeton Univ. Press, Princeton, USA, 310 pp. (1954)

22. B. Menendez, W. Zhu, and T-F. Wong, J. Struct. Geology, 18, 1-16 (1996)

23. A. DiGiovanni, J.T. Fredrich, D.J. Holcomb, and W.A. Olsson, In: J. Girard, M. Liebman, C. Breeds and T. Doe (eds), Proceedings North American Rock Mechanics Symposium, July 31, A.A. Balkema, Rotterdam, 1153-1158 (2000)

24. P. Baud, E. Klein, and T-F. Wong, J. Struct. Geology, 26, 603-624 (2004)

25. X. Lei, O. Nishizawa, K. Kusunose, and T. Satoh, J. Phys. of the Earth, 40, 617-634 (1992)

26. X. Lei, K. Kusunose, M.V.M.S. Rao, O. Nishizawa, and T. Satoh, JGR, 105, 6127-6139 (2000) 